\title{
BMJ Open Real-world effectiveness evaluation of budesonide/formoterol Spiromax for the management of asthma and chronic obstructive pulmonary disease in
} the UK

\author{
Jaco Voorham, ${ }^{1}$ Nicolas Roche, ${ }^{2}$ Hicham Benhaddi, ${ }^{3}$ Marianka van der Tol, ${ }^{4}$ \\ Victoria Carter, ${ }^{1}$ Job F.M. van Boven, ${ }^{5}$ Leif Bjermer, ${ }^{6}$ Marc Miravitlles, ${ }^{7}$ \\ David B Price ${ }^{1,8}$
}

To cite: Voorham J, Roche N, Benhaddi $\mathrm{H}$, et al. Real-world effectiveness evaluation of budesonide/ formoterol Spiromax for the management of asthma and chronic obstructive pulmonary disease in the UK. BMJ Open 2018;8:e022051. doi:10.1136/ bmjopen-2018-022051

- Prepublication history and additional material for this paper are available online. To view these files, please visit the journal online (http://dx.doi. org/10.1136/bmjopen-2018022051).

Received 2 February 2018 Revised 6 July 2018 Accepted 11 September 2018

Check for updates

(C) Author(s) (or their employer(s)) 2018. Re-use permitted under CC BY-NC. No commercial re-use. See rights and permissions. Published by BMJ.

For numbered affiliations see end of article.

Correspondence to

Dr Jaco Voorham; jaco@opri.sg

\section{ABSTRACT}

Objectives Budesonide/formoterol (BF) Spiromax ${ }^{\circledR}$ is an inhaled corticosteroid/long-acting $\beta_{2}$-agonist fixed-dose combination (FDC) inhaler, designed to minimise common inhaler errors and provide reliable and consistent dose delivery in asthma and chronic obstructive pulmonary disease (COPD). We evaluated non-inferiority of BF Spiromax after changing from another FDC inhaler, compared with continuing the original inhaler.

Methods Patients with asthma and/or COPD who switched to BF Spiromax were matched (1:3) with non-switchers. Data were obtained from the Optimum Patient Care Research Database and Clinical Practice Research Datalink in the UK. The primary end point was the proportion of patients achieving disease control (using the risk domain control (RDC) algorithm); secondary end points were: exacerbation rate, short-acting $\beta_{2}$-agonist (SABA) use and treatment stability (achieved RDC; no maintenance treatment change). Non-inferiority was defined as having $95 \% \mathrm{Cl}$ lower bound above $-10 \%$, using conditional logistic regression and adjusted for relevant confounders.

Results Comparing 385 matched patients (asthma 253; COPD 132) who switched to BF Spiromax with 1091 (asthma 743; COPD 348) non-switchers, non-inferiority of BF Spiromax in RDC was demonstrated (adjusted difference: $+6.6 \% ; 95 \% \mathrm{Cl}-0.3$ to 13.5$)$. Among patients with asthma, switchers to BF Spiromax versus BF Turbuhaler ${ }^{\circledR}$ reported fewer exacerbations (adjusted rate ratio (RR) $0.76 ; 95 \% \mathrm{Cl} 0.60$ to 0.99 ; $p=0.044$ ); were less likely to use high daily doses of SABA (adjusted OR $0.71 ; 95 \% \mathrm{Cl} 0.52$ to $0.98 ; p=0.034$ ); used fewer SABA inhalers (adjusted RR 0.92;95\% $\mathrm{Cl} 0.86$ to 0.99 ; $\mathrm{p}=0.019$ ); and were more likely to achieve treatment stability (adjusted OR 1.44;95\% Cl 1.02 to $2.04 ; p=0.037$ ). No significant differences in these end points were seen among patients with COPD.

Conclusions Among UK patients with asthma and COPD, real-world use of BF Spiromax was non-inferior to BF Turbuhaler in terms of disease control. Among patients with asthma, switching to BF Spiromax was associated with reduced exacerbations, reduced SABA use and

\section{Strengths and limitations of this study}

- Clearly defined a priori hypothesis, end points and sample size.

- A non-selective patient population, obtained through the use of real-world data from validated databases of primary care patients, with sufficient follow-up period for observing relevant outcomes.

- Hospital admissions, accident and emergency (A\&E) attendances and outpatient visits are not systematically recorded in primary care databases, and the applied definition to identify asthma-related hospital admissions or A\&E events may have given rise to false positive events.

- Potential effects of inhaler technique on the reported outcomes could not be taken into account, as this would require close observation and communication with each patient as they demonstrated their inhaler technique.

- Observed differences in secondary outcomes could have arisen as a consequence of factors unrelated to the inhalers that might not have been captured in the data set.

improved treatment stability versus continuing on BF Turbuhaler.

\section{INTRODUCTION}

Asthma and chronic obstructive pulmonary disease (COPD) are common respiratory conditions. $^{12}$ Cornerstone asthma/COPD treatment consists of inhaled therapy with proven efficacy in randomised clinical trials (RCTs). ${ }^{3} 4$ In real life, however, incorrect inhaler use is common in patients with asthma or COPD, resulting in poor symptom control and worse outcomes. ${ }^{56}$ Specifically, critical inhaler errors were reported in a review of 3660 patients; $^{7}$ insufficient respiratory effort 
in dry-powder inhaler (DPI) users and actuation before inhalation in metered-dose inhaler (MDI) users were found to be associated with uncontrolled asthma. ${ }^{7}$

In April 2014, marketing authorisation was granted for DuoResp $^{\circledR}$ Spiromax $^{\circledR}$ (Teva Pharmaceutical Industries, Petach Tikva, Israel), an inhaler containing a fixed-dose combination (FDC) of the inhaled corticosteroid (ICS) budesonide and the long-acting $\beta_{2}$-agonist (LABA) formoterol (budesonide/formoterol (BF)). The Spiromax inhaler was designed to maximise ease of use, reliability of dosing and consistency of lung deposition ${ }^{89}$ in patients with asthma or COPD. Spiromax is a breath-actuated, multidose DPI that is similar in design and appearance to MDI, but uses a different internal configuration. Drug delivery is via the $\mathrm{X}^{-\mathrm{ACT}^{\circledR}}{ }^{\circledR}$ system, consisting of active metering (on opening the cap, an air pump transfers the drug from the drug reservoir to the dose cup) and cyclone separator technology (turbulent airflow), which breaks up the dry-powder blend and separates fine drug particles from larger lactose particles. ${ }^{8}$ Spiromax requires only one preparation step (opening the cap) and provides consistent dose delivery across a broad range of inspiratory flow rates. ${ }^{89}$ Recent findings suggest that Spiromax is associated with a reduced number of errors related to dose preparation, undertaking the steps needed to correctly deliver the dose during inhalation and handling the device after inhalation, as well as being easier for patients and healthcare professionals to use compared with other DPIs. ${ }^{10} 11$ BF Spiromax has demonstrated pharmacokinetic bioequivalence to BF Turbuhaler ${ }^{\circledR}$ (AstraZeneca UK Limited, UK) in healthy volunteers. ${ }^{12}{ }^{13}$ A recent independent study of COPD found BF Spiromax to have a faster onset of bronchodilation than BF Turbuhaler, likely due to differences in drug deposition between the two devices. ${ }^{14}$ However, evidence for the real-world effectiveness of BF Spiromax in comparison with other inhalers in patients with asthma and/or COPD is lacking.

The current study was part of a multiphase assessment of real-world outcomes over 1 year in patients with asthma and/or COPD who switched to BF Spiromax compared with patients who remained on another device, using data from two UK primary care administrative databases. The primary objective of this phase of the study was to evaluate the non-inferiority of changing from another FDC inhaler to BF Spiromax versus continuing to use the original FDC inhaler, in terms of achieving disease control, based on the risk domain control (RDC) algorithm; secondary objectives included the effects of the switch on the occurrence of moderate/severe exacerbations and respiratory-related hospitalisations, treatment stability and short-acting $\beta 2$-agonist (SABA) use.

\section{METHODS}

\section{Patients and study design}

This was a matched, historic cohort study of patients with asthma and/or COPD using two validated primary care databases of patients in the UK, the Optimum Patient Care
Research Database (OPCRD) and the Clinical Practice Research Datalink (CPRD). ${ }^{15} 16$ OPCRD is governed by The Anonymous Data Ethics Protocols and Transparency committee, commissioned by the Respiratory Effectiveness Group. ${ }^{17}$ CPRD is a UK government research service, jointly supported by the National Institute for Health Research and the Medicines and Healthcare Products Regulatory Agency, that provides access to anonymised National Health Service (NHS) data. It operates under a range of UK and European laws as well as NHS and other guidelines. ${ }^{16}$ This study is registered with the European Network of Centres for Pharmacoepidemiology and Pharmacovigilance (Register number EUPAS13238). ${ }^{18}$

The OPCRD and CPRD databases were searched 2010 onwards to identify prescriptions of BF Spiromax, BF Turbuhaler and fluticasone propionate/salmeterol (FS) Accuhaler/Diskus (GlaxoSmithKline, Uxbridge, UK) in patients $\geq 18$ years of age with asthma and/or COPD (figure 1). The OPCRD and CPRD data sets for this study were constructed separately and checked for overlap before pooling to exclude duplicate patients. Patients had to have at least 2 years of data, comprising a minimum of one baseline year and 1 year of outcome period. Patients were required to have at least three prescriptions for ICS/ LABA FDC (BF Spiromax, BF Turbuhaler or FS Accuhaler $^{\circledR} /$ Diskus $^{\circledR}$ ) therapy during the baseline period. Switch patients must have evidence of an initial BF Spiromax prescription in the outcome period as well as at least one supplementary prescription for BF Spiromax in the 1 year outcome period to ensure consistent usage. Likewise, patients remaining on their inhaler required at least one repeat prescription in the outcome period. We only included patients switching to BF Spiromax who were registered at practices considered to have a policy of BF Spiromax adoption or wholesale change (ie, the decision to switch inhaler was based on cost savings instead of clinical reasons). Such practices were identified as those at which at least five patients changed to BF Spiromax within a 3-month period. The current study includes only patients who stayed on BF Turbuhaler or switched from $\mathrm{BF}$ Turbuhaler to BF Spiromax, due to the low number of patients who switched from FS Accuhaler/Diskus to BF Spiromax. The date of the first prescription of $\mathrm{BF}$ Spiromax or the (matched) date of the repeat prescription for BF Turbuhaler in the control arm was the index date. The recommended dosing instructions of BF Turbuhaler and BF Spiromax in adults are the same (asthma: one to two inhalations twice daily; COPD: two inhalations twice daily), and we observed no significant differences in prescribed dose between BF Spiromax and BF Turbuhaler in the disease groups.

Patients with asthma were required to have a diagnostic code (Read code) ${ }^{19}$ for asthma and/or at least two prescriptions for asthma therapy during the baseline year, and to have no other chronic respiratory disease diagnosis. Patients with COPD were required to be at least 40 years of age at first prescription for BF Spiromax or the matching BF Turbuhaler prescription, and to have 
OPCRD

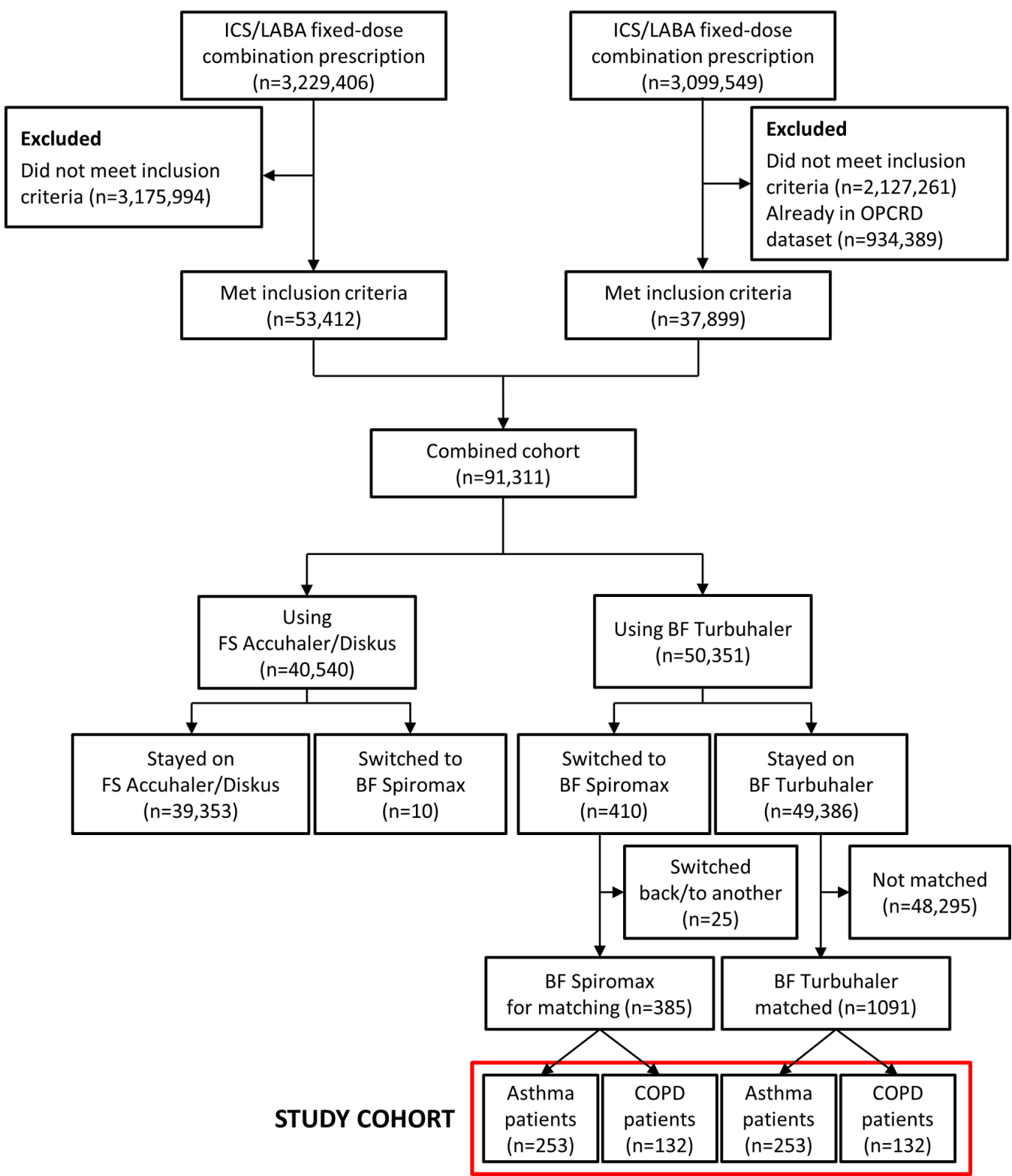

Figure 1 Patient flow diagram (prior to matching). BF, budesonide/formoterol; COPD, chronic obstructive pulmonary disease; CPRD, Clinical Practice Research Datalink; FS, fluticasone propionate/salmeterol; ICS, inhaled corticosteroid; LABA, longacting $\beta_{2}$-agonist; OPCRD, Optimum Patient Care Research Database.

a diagnostic code for COPD and a postbronchodilator $\mathrm{FEV}_{1} / \mathrm{FVC}<0.70$ consistent with the criteria for inclusion in the UK register of patients with COPD (Quality and Outcomes Framework). The subgroup of patients with only an asthma diagnosis is referred to henceforth as the asthma group. The patients with a COPD diagnosis (with or without an asthma diagnosis) are henceforth referred to as the COPD group.

\section{Outcome measures}

The primary outcome was disease control as assessed by RDC, a composite measure that has been used in several similar matched historical cohort studies to define absence of exacerbations. ${ }^{20-23}$ To achieve RDC in this study, patients must not have an asthma/COPD-related hospital admission, an asthma/COPD-related accident and emergency (A\&E) attendance or a course of oral corticosteroids (OCS) during the outcome period. In addition, patients in the COPD group must not have received antibiotics for a lower respiratory tract infection (LRTI).

Secondary outcomes included the number of moderate/severe exacerbations and hospitalisations, and change in treatment stability. A moderate/severe exacerbation (for COPD) or severe exacerbation (for asthma) was defined following the American Thoracic Society/ European Respiratory Society Task Force position statements. ${ }^{24}$ Lower respiratory hospitalisations were identified and classified as follows: definite hospitalisations were 
those with a lower respiratory code, including asthma and LRTI codes; or a generic hospitalisation Read code that has been recorded on the same day as a lower respiratory consultation; definite+probable hospitalisations were those occurring within a 7-day window (either side of the hospitalisation date) of a lower respiratory Read code. Adequate treatment stability was defined as achieving RDC and no increase in dose, change in delivery device, and change in type of ICS and/or use of LABAs, theophylline, long-acting muscarinic antagonists, or leukotriene receptor antagonists. ${ }^{22}$ Additional outcomes were SABA usage, which was expressed as average daily SABA dosage during the outcome year and calculated from prescriptions as ( Count of inhalers $\times$ doses in pack $\times \mu \mathrm{g}$ strength) /365), and a pneumonia event which was defined as having a Read coded diagnosis (probable pneumonia), or a Read coded diagnosis with a hospital admission or chest X-ray within 1 month (definite pneumonia).

\section{Statistical analyses}

It was estimated that 349 patients would have $90 \%$ power to demonstrate non-inferiority of BF Spiromax and BF Turbuhaler for achieving RDC, at a one-sided significance level of 0.050 . For the calculation, an expected difference in proportions of zero was used, assuming that the proportion of discordant pairs was 0.458 . This assumption was based on previous studies showing that a weighted average of $71.6 \%$ of patients with asthma and COPD prescribed FDC therapy have no exacerbations over a 1-year period. ${ }^{25} 26$

Descriptive statistics of all baseline demographic characteristics, comorbidities, medication use, indicators of disease severity and other patient characteristics were computed separately for the patients in the BF Spiromax and $\mathrm{BF}$ Turbuhaler groups and for patients in the asthma and COPD groups. In cases where multiple observations existed for a patient, one was randomly selected. Continuous variables were summarised using the number of non-missing observations, percentage of non-missing observations, mean, SD, median and IQR (difference between the 25th and 75th centiles), and a p value for the Kruskal-Wallis equality-of-populations rank test. Binary and categorical variables were summarised using the percentage of non-missing observations, the frequency and percentages (based on the non-missing sample size) of observed levels, and a $p$ value for the Pearson's $\chi^{2}$ test of independent categories.

Patients who switched to BF Spiromax were compared with matched controls who stayed on BF Turbuhaler. Mixed matching was performed 1:3 so that each BF Spiromax patient would be matched with up to three patients who remained on BF Turbuhaler (see supplementary methods in appendix for a full description of the mixed matching process). Mixed matching was performed to increase precision of the effect estimates. Because the analyses were conducted on all of the matched patients, which could introduce residual confounding due to imbalanced matching ratios, a sensitivity analysis was performed in which the outcome analyses were also performed in the subpopulation of patients in the BF Spiromax arm with exactly three matched patients in the BF Turbuhaler arm. Matching was performed using the most relevant confounders which were identified based on baseline imbalance and bias potential in relation to the primary outcome. For asthma, these confounders included age, gender, number of antibiotic courses, number of OCS courses, Global Initiative for Asthma control categories, number of exacerbations and RDC; matching confounders for COPD included age, gender, drug therapy, ICS average daily dose, number of antibiotic courses, number of exacerbations and Global Initiative for Chronic Obstructive Lung Disease risk categories. Baseline imbalance was assessed using the standardised mean difference (SMD), which, unlike a $\mathrm{p}$ value, is not affected by the number of observations in a sample, ${ }^{27} 28$ and provides information on the size of the difference. An SMD of $\leq 10 \%$ was assumed to represent sufficient balance between the arms, ${ }^{29}$ and the formula used is presented in the supplementary methods in appendix. Bias potential is the degree to which the observed association between the exposures of interest and the outcome is affected by conditioning on another variable; the formula is presented in the supplementary methods in appendix. A sensitive bias potential cut-off of $\geq 2 \%$ was used for this study.

Baseline variables with highest bias potential that were also insufficiently balanced were presented to a panel of experts for final selection. Following matching, the process was repeated in the matched sample to identify any residual confounding.

After mixed matching, conditional logistic regression of the between-patient difference in the primary outcome was performed to provide a 95\% CI with which to assess non-inferiority. Analyses were undertaken for the patients in the asthma and COPD groups combined, as well as by disease group. The model was adjusted for baseline variables that remained with bias potential after matching. Non-inferiority was claimed if the lower bound of the $95 \% \mathrm{CI}$ for the primary end point (RDC) was above $-10 \%$, a difference widely regarded as clinically important for many outcomes in respiratory studies, ${ }^{30} 31$ and used previously in similar real-life studies of patients in primary care settings. ${ }^{22}{ }^{23}$ If non-inferiority was achieved, superiority was tested.

Secondary outcomes were analysed in the matched sample and adjusted for baseline variables that remained with bias potential after matching, and reported as conditional rate ratios (RRs) or ORs with their 95\% CIs. Number of exacerbations and hospitalisations were analysed in the matched sample using conditional Poisson regression to obtain estimates of relative rates. Treatment stability was analysed in the matched sample using conditional logistic regression, and SABA usage was analysed in the matched sample using conditional ordinal logistic regression, after the SABA average daily dose was categorised. 
All statistical analyses were conducted using Stata MP6 V.12 and Stata SE V.14 (StataCorp, College Station, Texas, USA). A statistically significant result was defined as $\mathrm{p}<0.05$.

\section{Patient and public involvement}

No patients or public were involved in the design or conduct of this retrospective database study.

\section{RESULTS}

\section{Study population}

Overall, 420 patients switched to BF Spiromax (figure 1). Of the patients who used BF Turbuhaler, 410 switched to BF Spiromax and 49386 remained on BF Turbuhaler. Baseline characteristics of these unmatched patients are shown in supplementary table 1 , where imbalanced covariates $(\mathrm{SMD}>10 \%)$ for asthma include mean age, drug therapy, ICS average daily dose and number of exacerbations in baseline years; those for COPD include smoking status, drug therapy and ICS average daily dose.

For the matched analysis, a total of 385 patients switching to BF Spiromax were analysed; a total of 1091 patients who stayed on BF Turbuhaler were matched to the switch patients (figure 1). Twenty-five patients who switched back to BF Turbuhaler or to another FDC ICS/LABA were not included in the analysis. In the baseline characteristics of the matched patients, covariates with SMD $>10 \%$ in the asthma group were body mass index and ischaemic heart disease; for COPD they were smoking status, ischaemic heart disease, heart failure, number of exacerbations and number of acute OCS courses (table 1).

\section{Outcomes analyses}

Descriptive statistics of disease outcomes in the matched patients are shown in table 2. The FDC average daily dose was numerically lower among patients using BF Spiromax in the asthma group (382.1 $\mu \mathrm{g}$ vs $505.3 \mu \mathrm{g})$ and mean per cent RDC was higher among patients using BF Spiromax in both the asthma $(73.1 \%$ vs $68.0 \%)$ and COPD (40.2\% vs $37.1 \%$ ) groups (table 2 ).

The lower bound of the $95 \%$ CI of the adjusted percentage difference in the frequency of achieving RDC in the combined population was $-0.3 \%$, meeting the criterion for non-inferiority of switching to BF Spiromax compared with continuing on BF Turbuhaler (figure 2). Although a higher proportion of patients achieved RDC in the group that switched to BF Spiromax compared with patients who stayed on BF Turbuhaler, the difference was not statistically significant, and the mean betweengroup difference was less than the $10 \%$ considered to be clinically relevant. ${ }^{22} 233031$ In the sensitivity analysis where only BF Spiromax switchers that had three matched controls were used, a significant difference was shown in the combined patients group (adjusted \% difference 8.3; $95 \%$ CI $1.0 \%$ to $15.6 \%$; $\mathrm{p}=0.025$ ) (data not shown). In the sensitivity analysis, the adjusted percentage difference was nearly $10 \%$ in the COPD group but there was a wide
CI (adjusted \% difference 9.9; $95 \%$ CI $-2.4 \%$ to $22.2 \%$; $\mathrm{p}=0.114)$. Similarly, in the asthma group, the adjusted percentage difference was $6.5 \%$ (95\% CI $-2.7 \%$ to $15.7 \%$; $\mathrm{p}=0.168$ ). The conditional logistic regression model in all matched patients showed an adjusted OR of 1.31 (95\% CI 0.99 to $1.73 ; \mathrm{p}=0.061$ ) for BF Spiromax versus BF Turbuhaler for RDC, which did not achieve statistical significance. However, in the sensitivity analysis, the OR of 1.41 was statistically significant (95\% CI 1.05 to $1.90 ; p=0.022$ ) (data not shown).

Secondary outcomes shown are expressed as adjusted conditional RRs (figure 3a) and ORs (figure 3b) separately for patients with asthma and those with COPD. Among patients with asthma, switchers to BF Spiromax versus BF Turbuhaler reported fewer exacerbations, were less likely to use high amounts of SABA daily dose, used fewer SABA inhalers and were more likely to achieve treatment stability. Among patients with COPD, no significant differences in these end points were seen between those who switched to BF Spiromax and those staying on BF Turbuhaler. CIs for patients who switched to BF Spiromax show a trend effect for lower risk of being on high-dose SABA therapy and reduction in use of SABA inhalers in the COPD group. In the combined patients group, significance among switchers to BF Spiromax was noted in SABA average daily dose (OR $0.70 ; 95 \%$ CI 0.53 to $0.94 ; \mathrm{p}=0.017$ ), reduction in use of SABA inhalers (RR $0.94 ; 95 \%$ CI 0.89 to $0.99 ; \mathrm{p}=0.012$ ) and improved treatment stability (OR $0.74 ; 95 \%$ CI 0.56 to $0.99 ; \mathrm{p}=0.041$ ).

\section{DISCUSSION}

This study, the first to compare the real-world effectiveness of switching to the BF Spiromax inhaler from BF Turbuhaler, found that among 253 patients with asthma and 132 patients with COPD, BF Spiromax showed non-inferiority with respect to achievement of disease control to BF Turbuhaler in matched patients with asthma and/ or COPD. In the primary analysis in the combined population, patients who switched to BF Spiromax had 31\% higher odds of achieving RDC compared with those who remained on BF Turbuhaler; however, this finding did not meet the threshold for statistical significance.

Patients in the asthma group who switched to $\mathrm{BF}$ Spiromax had significantly reduced SABA use, fewer exacerbations and greater treatment stability compared with matched patients who remained on BF Turbuhaler. Some of the observed reductions in SABA use associated with BF Spiromax may have arisen as a result of patients using their new device as a reliever medication in addition to its use as maintenance therapy. The use of BF in a single-inhaler maintenance and quick-relief therapy regimen has been recommended as an improved method of administering ICS/LABA therapy. ${ }^{32}{ }^{33}$ However, the recommendations are not device-specific; as such, SABA use was not expected to differ between switchers to Spiromax and those who remained on Turbuhaler. The difference may be partially explained by the greater resemblance to an 


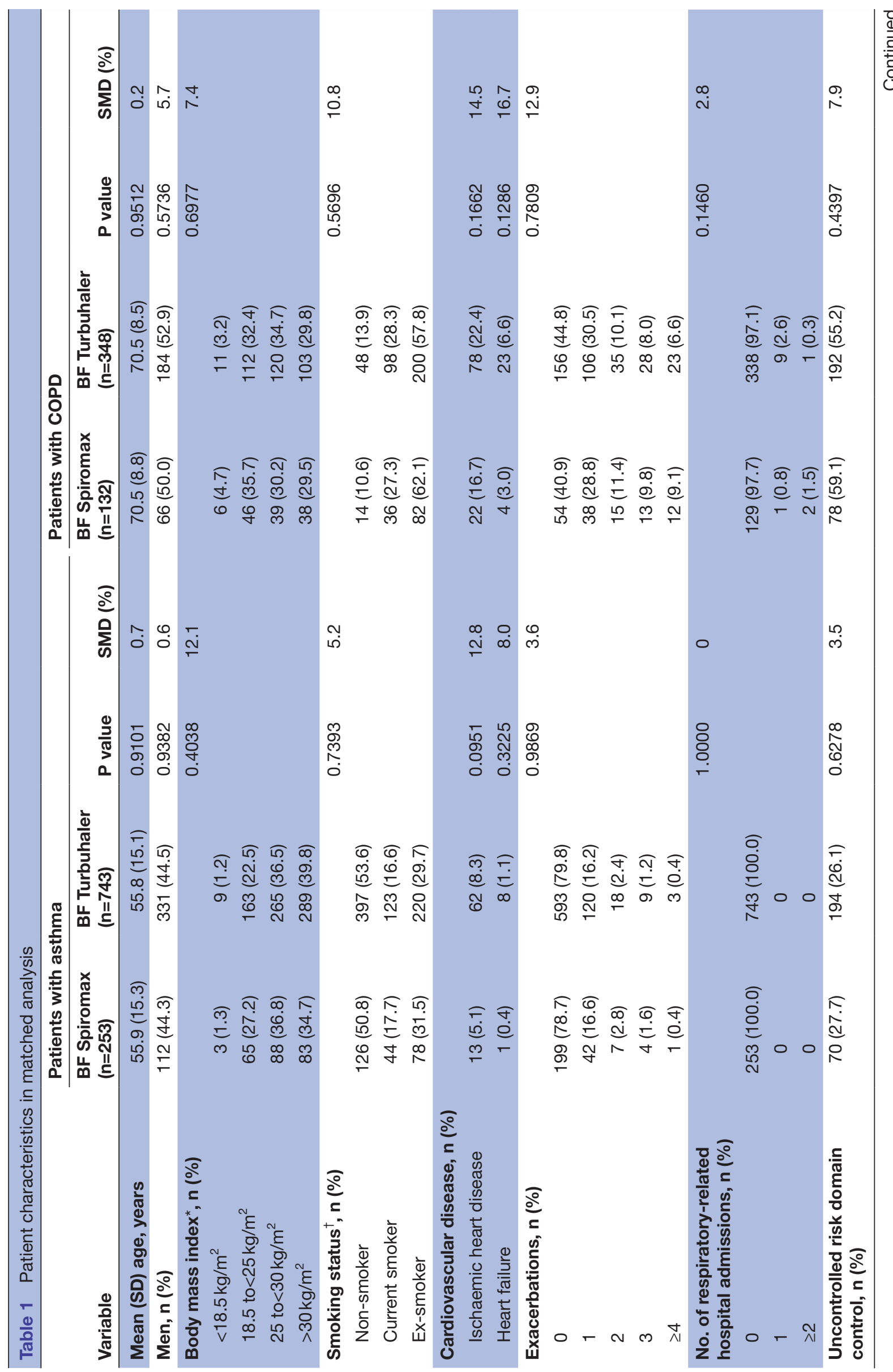




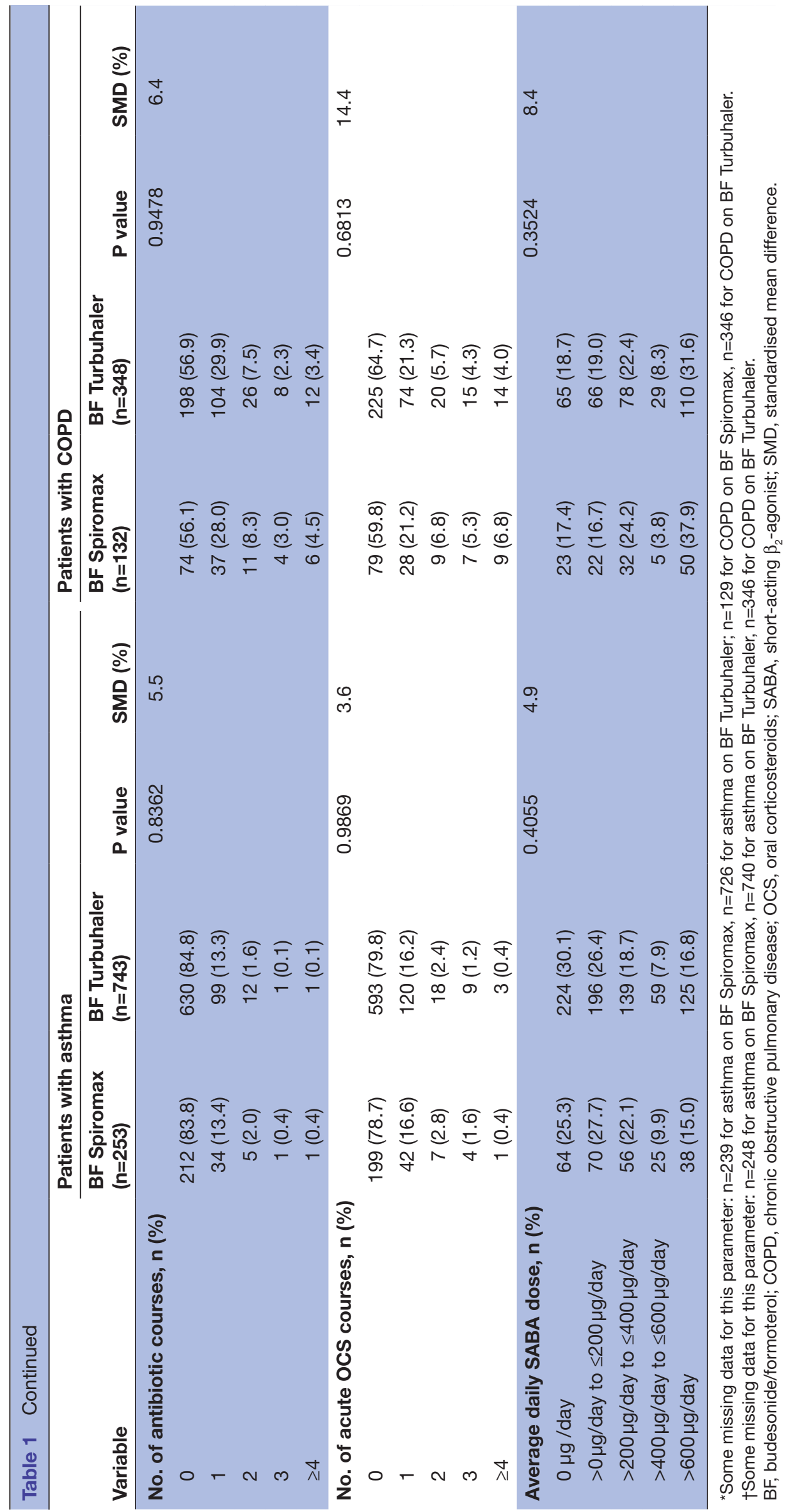


Table 2 Descriptive statistics of disease outcomes in the matched cohorts of patients.

\begin{tabular}{|c|c|c|c|c|}
\hline \multirow[b]{2}{*}{ Outcomes } & \multicolumn{2}{|c|}{ Patients with asthma } & \multicolumn{2}{|c|}{ Patients with COPD } \\
\hline & $\begin{array}{l}\text { BF Spiromax } \\
(\mathrm{n}=253)\end{array}$ & $\begin{array}{l}\text { BF Turbuhaler } \\
(n=743)\end{array}$ & $\begin{array}{l}\text { BF Spiromax } \\
(n=132)\end{array}$ & $\begin{array}{l}\text { BF Turbuhaler } \\
(\mathrm{n}=348)\end{array}$ \\
\hline$\%$ Risk domain control & 73.1 & 68.0 & 40.2 & 37.1 \\
\hline No. of exacerbations (SD) & $0.3(0.7)$ & $0.4(0.7)$ & $1.1(1.4)$ & $1.0(1.4)$ \\
\hline$\%$ Treatment stability & 72.7 & 66.9 & 39.4 & 37.1 \\
\hline SABA average daily dose (SD) & $1.4(1.9)$ & $1.5(2.9)$ & $2.6(2.9)$ & $2.4(2.3)$ \\
\hline No. of SABA inhalers (SD) & $5.1(6.8)$ & $5.5(10.7)$ & $9.5(11.0)$ & $8.7(8.5)$ \\
\hline No. of antibiotics prescriptions (SD) & $0.2(0.7)$ & $0.4(0.8)$ & $0.7(1.1)$ & $0.8(1.1)$ \\
\hline No. of acute OCS courses (SD) & $0.3(0.7)$ & $0.3(0.7)$ & $1.0(1.7)$ & $0.9(1.3)$ \\
\hline FDC ICS average daily dose (SD) & 382.1 (351.3) & $505.3(585.0)$ & $555.3(427.1)$ & $561.8(646.1)$ \\
\hline No. of FDC inhalers (SD) & $14.0(8.9)$ & $10.8(5.6)$ & $15.0(6.7)$ & $11.9(5.4)$ \\
\hline No. of respiratory A\&E attendances (SD) & $0.0(0.1)$ & $0.0(0.1)$ & $0.0(0.2)$ & $0.1(0.4)$ \\
\hline $\begin{array}{l}\text { No. of probable respiratory inpatient } \\
\text { hospitalisations (SD) }\end{array}$ & $0.0(0.1)$ & $0.0(0.1)$ & $0.1(0.4)$ & $0.1(0.5)$ \\
\hline $\begin{array}{l}\text { No. of definite respiratory inpatient } \\
\text { hospitalisations (SD) }\end{array}$ & $0.0(0.1)$ & $0.0(0.1)$ & $0.0(0.3)$ & $0.1(0.4)$ \\
\hline$\%$ Probable pneumonia* & 0.0 & 0.0 & 3.0 & 2.3 \\
\hline \% Definite pneumonia* & 0.0 & 0.0 & 2.3 & 0.6 \\
\hline
\end{tabular}

A\&E, accident and emergency; BF, budesonide/formoterol; COPD, chronic obstructive pulmonary disease; FDC, fixed-dose combination; ICS, inhaled corticosteroid; OCS, oral corticosteroid; SABA, short-acting $\beta_{2}$ agonist.

${ }^{*}$ A pneumonia event was defined as having a Read coded diagnosis (probable pneumonia), or a Read coded diagnosis with a hospital admission or chest X-ray within 1 month (definite pneumonia).

MDI device of Spiromax compared with Turbuhaler. No significant differences between patients who switched and those who did not were observed in the COPD group. This might be partly caused by lower statistical power in the COPD group, which included approximately half the number of patients as in the asthma group, and by the general notion that the reduction in exacerbation frequency with ICS is less in COPD compared with asthma. ${ }^{34}$ Another factor that could have contributed is the much older age ( 15 years) of patients in the COPD group. Age is a proxy for many health-related characteristics, and there is evidence of a negative correlation between advancing age and correct inhaler technique across MDI and the varying DPI devices. ${ }^{35}$

Switching asthma medications is often necessary for several reasons, including regaining or achieving asthma control or to constrain healthcare costs. Due to the retrospective design of our study, reasons for switching inhaler were not captured. However, we selected BF Spiromax patients registered at practices considered to have a policy of BF Spiromax adoption or wholesale change. While we cannot exclude some inhaler switches being induced by clinical reasons, the requirement for practices to have at least five patients switch to BF Spiromax within a 3-month

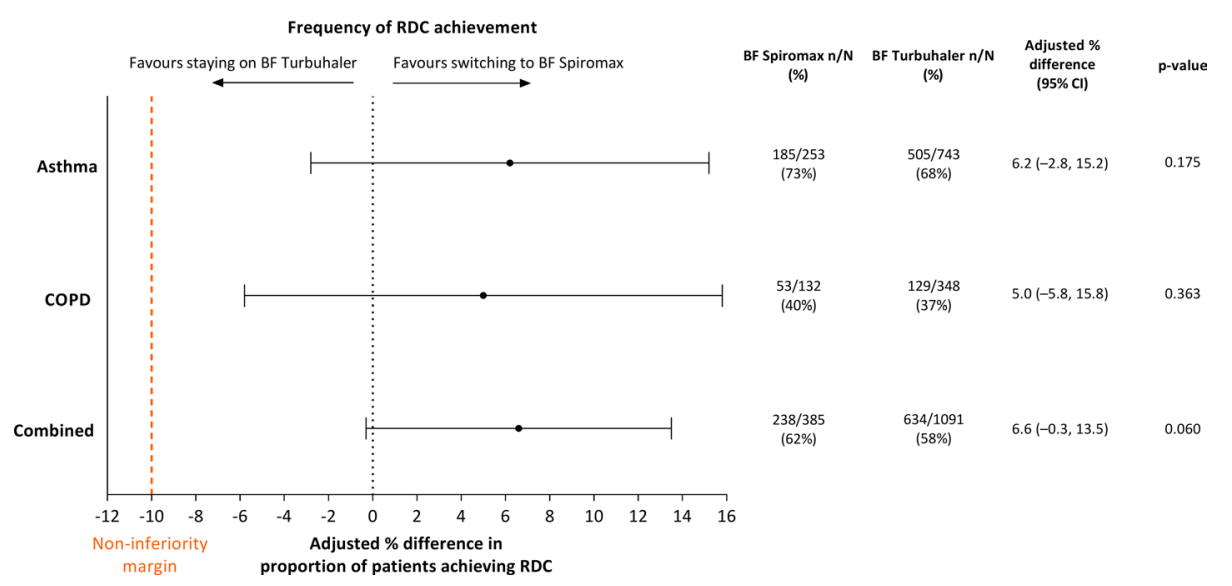

Figure 2 Frequency of achievement of RDC in patients switching to BF Spiromax and those continuing on BF Turbuhaler. BF, budesonide/formoterol; COPD, chronic obstructive pulmonary disease; RDC, risk domain control. 


\section{A}

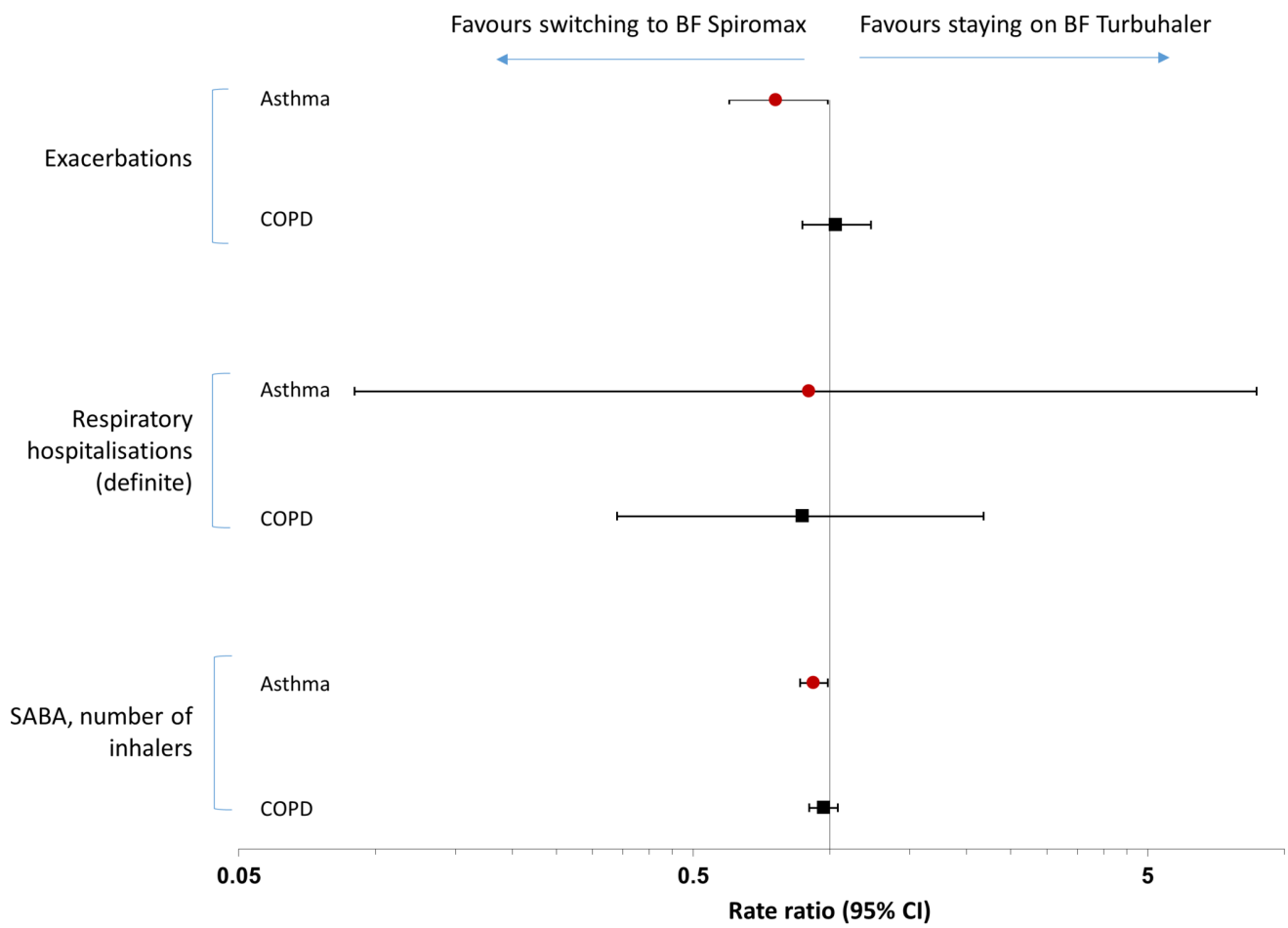

Rate ratio (95\% Cl)

P-value

$0.76(0.60-0.99)$

0.044

$1.03(0.87-1.23)$

0.712

$0.90(0.09-8.68)$

0.925

$0.87(0.34-2.18)$

0.762

$0.92(0.86-0.99)$

0.019

$0.97(0.90-1.04)$

0.363

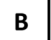

B

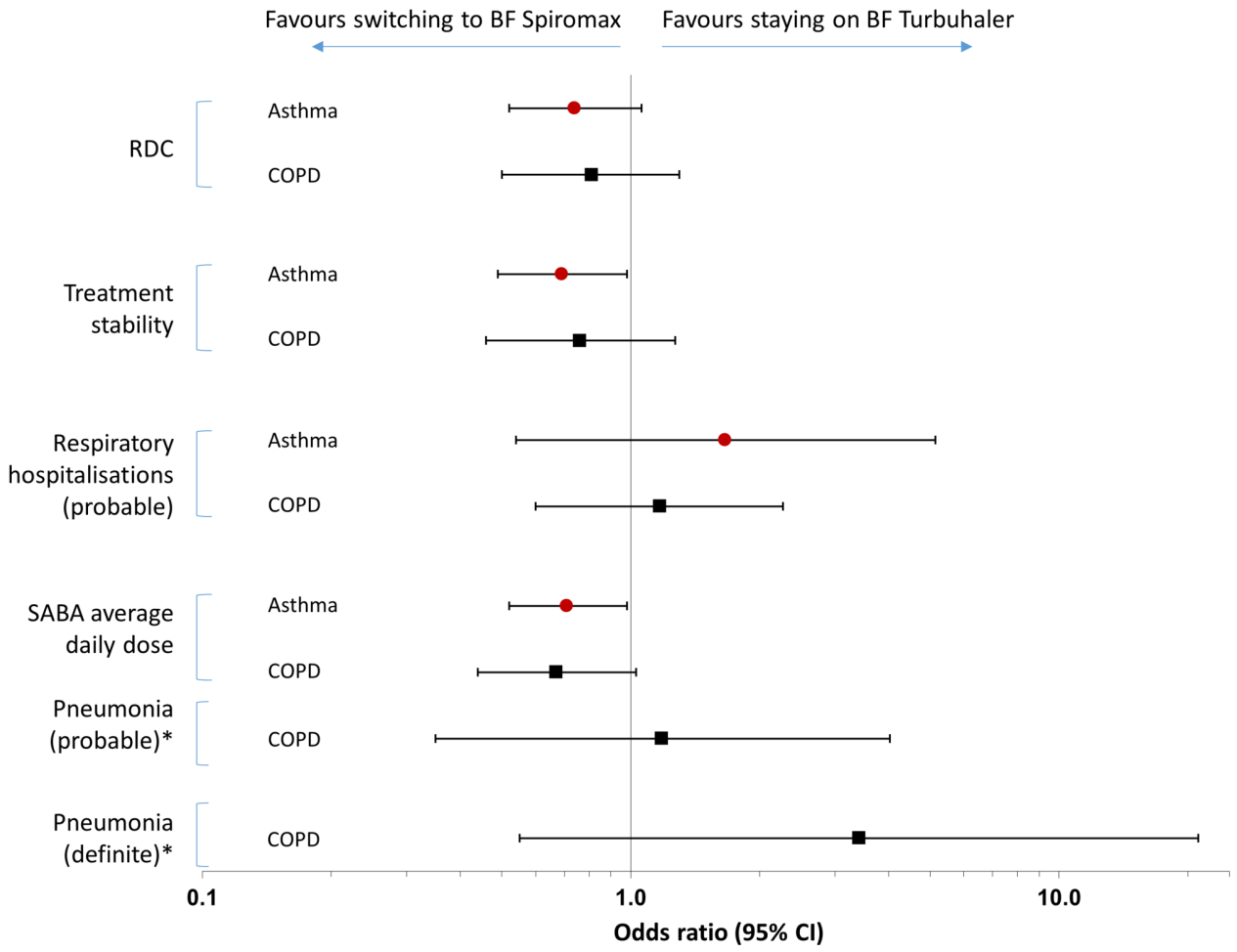

Odds ratio $(95 \% \mathrm{Cl})$

P-value

$0.74(0.52-1.06)$

0.100

$0.81(0.50-1.30)$

0.372

$0.69(0.49-0.98)$

0.037

$0.76(0.46-1.27)$

0.296

$1.66(0.54-5.15)$

0.378

$1.17(0.60-2.27)$

0.643

$0.71(0.52-0.98)$

0.034

$0.67(0.44-1.03)$

0.069

$1.18(0.35-4.03)$

0.789

$3.41(0.55-21.13)$

0.187

Figure 3 Clinical outcomes expressed as adjusted conditional $(A)$ rate ratios $(95 \% \mathrm{Cl})$ and $(\mathrm{B})$ ORs $(95 \% \mathrm{Cl})$, among patients switching to BF Spiromax versus continuing on BF Turbuhaler in the matched analysis. ${ }^{*}$ Model did not converge in the asthma group. BF, budesonide/formoterol; COPD, chronic obstructive pulmonary disease; RDC, risk domain control; SABA, shortacting $\beta_{2}$ agonist.

period means that in our view it is probable that many of the switches to BF Spiromax at these centres were driven by economic rationales. Thus, it is expected that any differences between treatments in our study result from the switch in inhalers rather than improvement in poor disease control. A switch to a different inhaler may 
potentially increase patient-practice contact, in terms of additional evaluation and teaching of inhaler technique, which may confound the results. However, in a pilot study which has been published only in abstract form, ${ }^{36} 76 \%$ of 114 patients were switched to BF Spiromax without consultation, suggesting that any confounding created by additional physician teaching for those who switched versus those remaining on original therapy was limited in the overall patient population. Indeed, previous findings have shown that most patients with asthma who have had their inhaler device switched without their consent believed that cost issues were a factor. ${ }^{37}$ As such, it is likely that many of the switches experienced by our patient cohort took place at least in part for economic reasons.

The results observed in this real-world study are consistent with previous evidence gained from RCTs where BF Spiromax was found to have similar efficacy to BF Turbuhaler. $^{38}$ The suggestion of potential superiority on secondary outcome measures in the current study, a result which was not seen in RCTs, might plausibly reflect differences in ease of use and/or adherence between the inhalers when prescribed in routine care. Patients participating in respiratory RCTs usually represent only between $1 \%$ and $5 \%$ of the true population of patients with asthma or $\mathrm{COPD}^{39}$ and the proportion of patients with COPD in primary care who would be eligible for inclusion in recent large pharmaceutically sponsored COPD studies has ranged from $17 \%$ to $42 \% .{ }^{40}$ In addition, adherence to treatment in real-world observational studies is usually much lower than in RCTs. ${ }^{41}$ Moreover, proper inhaler technique is often artificially high in clinical trials because of patient selection, extensive training, and close monitoring, which may explain why minimal differences in outcomes between devices have been observed in RCTs. ${ }^{42}$ However, in daily practice, patients' differential ability to correctly use their inhaler may result in larger differences in health outcomes. Previous studies have shown that study participants and healthcare professionals find it easier to learn how to use the Spiromax inhaler correctly, compared with other DPIs. ${ }^{10}{ }^{11}$ Furthermore, patients are able to achieve slightly higher peak inspiratory flow rates with the Spiromax inhaler compared with the Turbuhaler. ${ }^{43}$

This study had a clearly defined a priori hypothesis, end points and sample size, as is recommended for this type of observational research. ${ }^{44}$ A particular strength was the non-selective patient population obtained through the use of real-world data from validated databases of primary care patients. The size and scope of these databases allowed for the collection of important clinical variables and a sufficient follow-up period for observing relevant outcomes. In addition, the study's time horizon of 1 year has minimised the impact of potential seasonal differences in disease activity. ${ }^{45}$ Overall, the study was well powered to investigate the primary outcome which was RDC of disease.

The inclusion of matched patients in our analysis of RDC risked introducing residual confounding due to imbalanced matching ratios. We therefore performed a sensitivity analysis in the subpopulation of patients in the BF Spiromax arm with exactly three matched patients in the BF Turbuhaler arm. Compared with patients who remained on BF Turbuhaler, patients who switched to BF Spiromax had $31 \%$ and $41 \%$ higher odds of achieving RDC in the primary analysis and sensitivity analysis, respectively, with the difference reaching statistical significance in the sensitivity analysis only. Regardless of whether significance was achieved, the difference in odds with BF Spiromax versus BF Turbuhaler is quite similar between the primary and sensitivity analyses, supporting the overall validity of our assumptions for the effect of BF Spiromax versus BF Turbuhaler on achieving disease control.

Limitations of the study are important to note. The use of databases to evaluate outcomes depends on the information registered, which is for clinical and routine use rather than research purposes. Possible issues include the fact that hospital admissions, A\&E attendances and outpatient visits are not systematically recorded in primary care databases and the applied definition to identify asthma-related hospital admissions or A\&E events may give false positive events. However, this limitation would apply equally to both groups. In addition, inhaler technique could not be taken into account for this study as this would require close observation and communication with each patient as they demonstrated their inhaler technique. Regarding the secondary outcomes, we cannot rule out the possibility that the observed differences were caused by factors unrelated to the inhalers, as patients who switched to BF Spiromax may have differed from non-switchers in ways not captured in our data set. Comparison with other ICS/LABA FDCs would have been useful to determine any differences attributable to pharmacological effect; however, there were insufficient patient numbers for such comparisons. An important limitation in observational studies is the potential for confounding of the associations arising from systematic differences between the patients being compared. In this study, confounding was minimised where possible using matching techniques to create cohorts that were comparable in terms of important demographic and clinical characteristics as recommended by the Respiratory Effectiveness Group. ${ }^{44}$ Multivariate models were adjusted by those variables that continued to confound the associations of interest after matching. However, in the COPD group, due to a limited number of patients, only a restricted set of variables could be used for matching and model adjustment. Therefore, we cannot ensure confounding of the association of interest was sufficiently addressed in this group. Furthermore, as previously discussed, the selection of patients from practices which were required to have at last five switchers to BF Spiromax in a 3-month period could potentially have introduced a bias in favour of practices with greater than average asthma/COPD expertise and involvement in care of patients with asthma/COPD. 
This real-world analysis showed that switching from BF Turbuhaler to BF Spiromax was associated with no loss of symptom control and may be beneficial in some patients. These data validate, in a real-world population of patients with asthma and COPD and clinical setting, similar efficacy to that previously demonstrated in an $\mathrm{RCT}^{38}$ Such validation is important for primary practitioners as it provides reassurance that BF Spiromax is effective in realworld primary care patients, and not just in the carefully selected and closely monitored cohorts of patients typical of RCTs. It should however be noted that periodical assessments of adherence, motivation and inhaler technique are still likely to be required to ensure that optimal inhaler use is maintained in the long term. ${ }^{46-51}$ Further research may be needed to assess the extent to which the results of this analysis are generalisable to patients outside of the UK.

\section{Author affiliations}

${ }^{1}$ Observational and Pragmatic Research Institute Pte Ltd, Singapore, Singapore ${ }^{2}$ Hôpitaux Universitaires Paris Centre, Cochin Hospital (APHP), University Paris Descartes (EA2511), Paris, France

${ }^{3}$ Global Health Economics \& Outcomes Research, Teva Pharmaceuticals, Wilrijk, Belgium

${ }^{4}$ Respiratory Devices, Teva Pharmaceuticals Europe B.V, Amsterdam, The Netherlands

${ }^{5}$ Department of General Practice \& Elderly Care, Groningen Research Institute for Asthma and COPD (GRIAC), University Medical Centre Groningen, University of Groningen, Groningen, The Netherlands

${ }^{6}$ Respiratory Medicine and Allergology, Skåne University Hospital, Lund, Sweden ${ }^{7}$ Department of Pneumology, Hospital Universitari Vall d'Hebron, CIBER de Enfermedades Respiratorias (CIBERES), Barcelona, Spain

${ }^{8}$ Centre of Academic Primary Care, University of Aberdeen, Aberdeen, UK

Acknowledgements The authors thank Derek Skinner, Francis Appiagyei and Tanith Hjelmbjerg of the Observational and Pragmatic Research Institute for providing assistance with data analysis. The authors also thank lan Grieve and Bill Watkins of Ashfield Healthcare Communications, part of UDG Healthcare, for providing medical writing support. The authors thank Teva Pharmaceuticals for providing a full review of the article.

Contributors All authors (JV, NR, HB, MvdT, VC, JFMvB, LB, MM, DBP) were involved in the conception and design of the study. JV was responsible for the analysis of the data. All authors (JV, NR, HB, MvdT, VC, JFMvB, LB, MM, DBP) interpreted the data, were involved in development of the manuscript and completed critical reviews. The authors were fully responsible for all content and editorial decisions, were involved at all stages of manuscript development, and have approved the final version.All authors (JV, NR, HB, MvdT, VC, JFMvB, LB, MM, DBP) meet the International Committee of Medical Journal Editors (ICMJE) criteria for authorship for this manuscript, take responsibility for the integrity of the work as a whole, and have given final approval to the version to be published. JV is guarantor of the study.

Funding This study was supported by Teva Pharmaceuticals and undertaken by OPRI (http://opri.sg). Medical writing support was funded by Teva Pharmaceuticals.

Competing interests JV and VC are employees of OPRI, which has conducted paid research in respiratory disease on behalf of the following organisations in the past 5 years: Aerocrine, AKL Research and Development Ltd, Almirall, AstraZeneca, Boehringer Ingelheim, Chiesi, GlaxoSmithKline, Meda, Mundipharma, Napp, Novartis, Orion, Takeda, Teva, Zentiva (a Sanofi company). NR reports grants and personal fees from Boehringerlngelheim, Novartis, and personal fees from Teva, GSK, AstraZeneca, Chiesi, Mundipharma, Cipla, Sanofi, Sandoz, 3M, Pfizer, Zambon, outside the presented work. HB is an employee of Teva Pharmaceuticals. MvdT was an employee of Teva Pharmaceuticals Europe BV at the time the study was conducted. JFMvB has received consultancy fees from AstraZeneca, speaker fees from Menarini, research support from GSK, Boehringer Ingelheim, Astrazeneca and Chiesi and travel support from the European COPD Coalition and the Respiratory Effectiveness Group. LB has during the last 3 years received honoraria to participate or to give lectures for the following companies: ALK, AstraZeneca, Boehringer, Chiesi, GlaxoSmithklein, Novartis and Teva. MM declares no relevant competing interests. DBP has board membership with Aerocrine, Amgen, AstraZeneca, Boehringer Ingelheim, Chiesi, Mylan, Mundipharma, Napp, Novartis, and Teva Pharmaceuticals; consultancy agreements with Almirall, Amgen, AstraZeneca, Boehringer Ingelheim, Chiesi, GlaxoSmithKline, Mylan, Mundipharma, Napp, Novartis, Pfizer, Teva Pharmaceuticals and Theravance; grants and unrestricted funding for investigator initiated studies (conducted through Observational and Pragmatic Research Institute Pte Ltd) from Aerocrine, AKL Research and Development Ltd, AstraZeneca, Boehringer Ingelheim, British Lung Foundation, Chiesi, Mylan, Mundipharma, Napp, Novartis, Pfizer, Respiratory Effectiveness Group, Teva Pharmaceuticals, Theravance, UK National Health Service, Zentiva; payment for lectures/speaking engagements from Almirall, AstraZeneca, Boehringer Ingelheim, Chiesi, Cipla, GlaxoSmithKline, Kyorin, Mylan, Merck, Mundipharma, Novartis, Pfizer, Skyepharma, and Teva Pharmaceuticals; payment for manuscript preparation from Mundipharma and Teva Pharmaceuticals; payment for the development of educational materials from Mundipharma and Novartis; payment for travel/accommodation/meeting expenses from Aerocrine, AstraZeneca, Boehringer Ingelheim, Mundipharma, Napp, Novartis, and Teva Pharmaceuticals; funding for patient enrolment or completion of research from Chiesi, Novartis, Teva Pharmaceuticals, and Zentiva; stock/stock options from AKL Research and Development Ltd which produces phytopharmaceuticals; owns $74 \%$ of the social enterprise Optimum Patient Care Ltd (Australia, Singapore and UK) and $74 \%$ of Observational and Pragmatic Research Institute Pte Ltd (Singapore); and is peer reviewer for grant committees of the Efficacy and Mechanism Evaluation programme, and Health Technology Assessment.

Patient consent Not required.

Ethics approval This study was approved by the Anonymised Data Ethics Protocols and Transparency (ADEPT) committee (reference ADEPT0816), the independent scientific advisory committee for the OPCRD, commissioned by the Respiratory Effectiveness Group, and the Independent Scientific Advisory Committee (ISAC) for the CPRD (registration number, 16_086), The study was designed, implemented, and registered in accordance with the criteria of the European Network of Centres for Pharmacoepidemiology and Pharmacovigilance (ENCEPP/SDPP/13238). The CPRD has broad National Research Ethics Service Committee (NRES) ethics approval for purely observational research using the primary care data and established data linkages. The OPCRD has ethical approval from the National Health Service (NHS) Research Authority to hold and process anonymised research data (Research Ethics Committee reference: 15/EM/0150).

Provenance and peer review Not commissioned; externally peer reviewed.

Data sharing statement All relevant data are within the paper and its Supporting Information files. The data set supporting the conclusions of this article was derived from the Clinical Practice Research Datalink (www.cprd.com) and the UK Optimum Patient Care Research Database (www.opcrd.co.uk). We do not have permission to give public access to these databases; however, researchers may request access for their own purposes.

Open access This is an open access article distributed in accordance with the Creative Commons Attribution Non Commercial (CC BY-NC 4.0) license, which permits others to distribute, remix, adapt, build upon this work non-commercially, and license their derivative works on different terms, provided the original work is properly cited, appropriate credit is given, any changes made indicated, and the use is non-commercial. See: http://creativecommons.org/licenses/by-nc/4.0/.

\section{REFERENCES}

1. Masoli M, Fabian D, Holt S, et al. The global burden of asthma: executive summary of the GINA Dissemination Committee report. Allergy 2004;59:469-78.

2. Adeloye D, Chua S, Lee C, et al. Global and regional estimates of COPD prevalence: Systematic review and meta-analysis. J Glob Health 2015;5:020415.

3. Global Initiative for Asthma. 2017 Report. http://ginasthma.org/ wp-content/uploads/2016/01/wms-GINA-2017-main-report-trackedchanges-for-archive.pdf (accessed 29 May 2018).

4. Vogelmeier CF, Criner GJ, Martinez FJ, et al. Global strategy for the diagnosis, management, and prevention of chronic obstructive lung disease 2017 report: gold executive summary. Eur Respir J 2017;49:1700214. 
5. Lavorini F, Magnan A, Dubus JC, et al. Effect of incorrect use of dry powder inhalers on management of patients with asthma and COPD. Respir Med 2008;102:593-604.

6. Al-Jahdali H, Ahmed A, Al-Harbi A, et al. Improper inhaler technique is associated with poor asthma control and frequent emergency department visits. Allergy Asthma Clin Immunol 2013;9:8.

7. Price DB, Román-Rodríguez M, McQueen RB, et al. Inhaler errors in the critikal study: type, frequency, and association with asthma outcomes. J Allergy Clin Immunol Pract 2017;5:1071-81.

8. Canonica GW, Arp J, Keegstra JR, et al. Spiromax, a new dry powder inhaler: dose consistency under simulated real-world conditions. $J$ Aerosol Med Pulm Drug Deliv 2015;28:309-19.

9. Chrystyn H, Safioti G, Keegstra JR, et al. Effect of inhalation profile and throat geometry on predicted lung deposition of budesonide and formoterol (bf) in copd: an in-vitro comparison of spiromax with turbuhaler. Int J Pharm 2015;491(1-2):268-76.

10. Sandler N, Holländer J, Långström D, et al. Evaluation of inhaler handling-errors, inhaler perception and preference with spiromax easyhaler and turbuhaler devices among healthy finnish volunteers: a single site, single visit crossover study (Finhaler). BMJ Open Respir Res 2016;3:e000119.

11. Bosnic-Anticevich $\mathrm{S}$, Callan $\mathrm{C}$, Chrystyn $\mathrm{H}$, et al. Inhaler technique mastery and maintenance in healthcare professionals trained on different devices. J Asthma 2018;55:79-88.

12. Weisfeld L, Gopalan G, Shu Y, et al. Pharmacokinetics (PK) and safety of budesonide plus formoterol (BF) $(160 / 4.5 \mathrm{mcg})$ Spiromax ( and BF $(200 / 6 \mathrm{mcg})$ Turbuhaler $®$ following two inhalations (+/charcoal [char] block) in healthy volunteers (HV). Eur Resp J 2013a;42:P712.

13. Weisfeld L, Gopalan G, Shu Y, et al. Pharmacokinetics (PK) and safety of budesonide plus formoterol (BF) $(320 / 9 \mathrm{mcg})$ Spiromax ${ }^{\circledR}$ and BF $(400 / 12 \mathrm{mcg})$ Turbuhaler $\AA$ following two inhalations (+/- charcoal [char] block) in healthy volunteers (HV). Eur Resp J 2013b;42:4630.

14. Cazzola M, Ora J, Di Paolo A, et al. Onset of action of budesonide/ formoterol Spiromax ${ }^{\circledR}$ compared with budesonide/formoterol Turbuhaler ${ }^{\circledR}$ in patients with COPD. Pulm Pharmacol Ther 2016;39:48-53.

15. Optimum Patient Care Research Database (OPCRD). http:// optimumpatientcare.org/database-overview/ (accessed 29 May 2018).

16. Clinical Practice Research Datalink. https://www.cprd.com/home/ (accessed 29 May 2018).

17 Respiratory Effectiveness Group. http://effectivenessevaluation.org/ about-us/ (accessed 29 May 2018)

18. European network of centres for pharmacoepidemiology and pharmacovigilance. http://www.encepp.eu/ (accessed 29 May 2018)

19. Digital NHS. Read codes. https://digital.nhs.uk/article/1104/ReadCodes (accessed 29 May 2018).

20. Price D, Martin RJ, Barnes N, et al. Prescribing practices and asthma control with hydrofluoroalkane-beclomethasone and fluticasone: a real-world observational study. J Allergy Clin Immunol 2010;126:511-8

21. Price DB, Colice G, Israel E, et al. Add-on LABA in a separate inhaler as asthma step-up therapy versus increased dose of ICS or ICS/ LABA combination inhaler. ERJ Open Res 2016;2:00106-2015-2015.

22. Price $D$, Thomas $V$, von Ziegenweidt $J$, et al. Switching patients from other inhaled corticosteroid devices to the Easyhaler®: historical, matched-cohort study of real-life asthma patients. J Asthma Allergy 2014;7:31-51.

23. Price D, Small I, Haughney J, et al. Clinical and cost effectiveness of switching asthma patients from fluticasone-salmeterol to extrafine particle beclometasone-formoterol: a retrospective matched observational study of real-world patients. Prim Care Respir J 2013;22:439-48.

24. Reddel HK, Taylor DR, Bateman ED, et al. An official American Thoracic Society/European Respiratory Society statement: asthma control and exacerbations: standardizing endpoints for clinical asthma trials and clinical practice. Am J Respir Crit Care Med 2009;180:59-99.

25. Hagedorn C, Kässner F, Banik N, et al. Influence of salmeterol/ fluticasone via single versus separate inhalers on exacerbations in severe/very severe COPD. Respir Med 2013;107:542-9.

26. Israel E, Roche N, Martin RJ, et al. Increased dose of inhaled corticosteroid versus add-on long-acting $\beta$-agonist for step-up therapy in asthma. Ann Am Thorac Soc 2015;12:798-806.

27. Stuart EA, lalongo NS. Matching methods for selection of subjects for follow-up. Multivariate Behav Res 2010;45:746-65.
28. Rosenbaum PR, Rubin DB. Constructing a control group using multivariate matched sampling methods that incorporate the propensity score. The American Statistician 1985;39:33-8.

29. Austin PC. An introduction to propensity score methods for reducing the effects of confounding in observational studies. Multivariate Behav Res 2011;46:399-424.

30. Huitfeldt B, Hummel J. The draft FDA guideline on non-inferiority clinical trials: a critical review from European pharmaceutical industry statisticians. Pharm Stat 2011;10:414-9.

31. Chapman KR, Bergeron C, Bhutani M, et al. Do we know the minimal clinically important difference (MCID) for COPD exacerbations? COPD 2013;10:243-9.

32. Chapman KR, Barnes NC, Greening AP, et al. Single maintenance and reliever therapy (SMART) of asthma: a critical appraisal. Thorax 2010;65:747-52.

33. Thomas M, Pavord I. Single inhaler maintenance and reliever therapy (SMART) in general practice asthma management: where are we? Prim Care Respir J 2012;21:8-10.

34. Calverley PM. Effect of corticosteroids on exacerbations of asthma and chronic obstructive pulmonary disease. Proc Am Thorac Soc 2004;1:161-6.

35. Barbara S, Kritikos V, Bosnic-Anticevich S, et al. Inhaler technique: does age matter? A systematic review. Eur Respir Rev 2017;26:26.

36. Benhaddi $\mathrm{H}$, et al. Real-life effectiveness of budesonide/ formoterol for the management of asthma and COPD. Eur Respir $J$ 2016;48:PA627.

37. Doyle S, Lloyd A, Williams A, et al. What happens to patients who have their asthma device switched without their consent? Prim Care Respir J 2010;19:131-9.

38. Virchow JC, Rodriguez-Roisin R, Papi A, et al. A randomized, double-blinded, double-dummy efficacy and safety study of budesonide-formoterol Spiromax ${ }^{\circledR}$ compared to budesonideformoterol Turbuhaler $\AA^{\circledR}$ in adults and adolescents with persistent asthma. BMC Pulm Med 2016;16:42.

39. Herland K, Akselsen JP, Skjønsberg $\mathrm{OH}$, et al. How representative are clinical study patients with asthma or COPD for a larger "real life" population of patients with obstructive lung disease? Respir Med 2005;99:11-19.

40. Kruis AL, Ställberg B, Jones RC, et al. Primary care COPD patients compared with large pharmaceutically-sponsored COPD studies: an UNLOCK validation study. PLoS One 2014;9:e90145.

41. Price D, Brusselle G, Roche N, et al. Real-world research and its importance in respiratory medicine. Breathe 2015;11:26-38.

42. Dolovich MB, Ahrens RC, Hess DR, et al. Device selection and outcomes of aerosol therapy: Evidence-based guidelines: American College of Chest Physicians/American college of asthma, allergy, and immunology. Chest 2005;127:335-71.

43. Azouz W, Chetcuti P, Hosker H, et al. Inhalation characteristics of asthma patients, COPD patients and healthy volunteers with the Spiromax $₫$ and Turbuhaler $\AA$ devices: a randomised, cross-over study. BMC Pulm Med 2015;15:47.

44. Roche N, Reddel H, Martin R, et al. Quality standards for realworld research. Focus on observational database studies of comparative effectiveness. Ann Am Thorac Soc 2014;11 Supp 2:S99-S104.

45. Jenkins CR, Celli B, Anderson JA, et al. Seasonality and determinants of moderate and severe COPD exacerbations in the TORCH study. Eur Respir J 2012;39:38-45.

46. Broeders ME, Sanchis J, Levy ML, et al. The ADMIT series-issues in inhalation therapy. 2. Improving technique and clinical effectiveness. Prim Care Respir J 2009;18:76-82.

47. Ovchinikova L, Smith L, Bosnic-Anticevich S. Inhaler technique maintenance: gaining an understanding from the patient's perspective. J Asthma 2011;48:616-24.

48. Bosnic-Anticevich SZ, Sinha H, So S, et al. Metered-dose inhaler technique: the effect of two educational interventions delivered in community pharmacy over time. J Asthma 2010;47:251-6.

49. Crane MA, Jenkins CR, Goeman DP, et al. Inhaler device technique can be improved in older adults through tailored education: findings from a randomised controlled trial. NPJ Prim Care Respir Med 2014;:24:14034.

50. Klijn SL, Hiligsmann M, Evers S, et al. Effectiveness and success factors of educational inhaler technique interventions in asthma \& COPD patients: a systematic review. NPJ Prim Care Respir Med 2017;27:24

51. Greenland S. Modeling and variable selection in epidemiologic analysis. Am J Public Health 1989;79:340-9. 
Correction: Real-world effectiveness evaluation of

budesonide/formoterol Spiromax for the management of asthma and chronic obstructive pulmonary disease in the UK

Voorham J, Roche N, Benhaddi H, et al. Real-world effectiveness evaluation of budesonide/formoterol Spiromax for the management of asthma and chronic obstructive pulmonary disease in the UK. BMJ Open 2018;8:e022051. doi: 10.1136/ bmjopen-2018-022051.

The previous version of this manuscript doesn't present a COI and is missing in the article. It should read as:

MM has received speaker or consulting fees from AstraZeneca, Bial, Boehringer Ingelheim, Chiesi, Cipla, CSL Behring, Laboratorios Esteve, Gebro Pharma, GlaxoSmithKline, Grifols, Menarini, Mereo Biopharma, Novartis, pH Pharma, Rovi, TEVA, Verona Pharma and Zambon, and research grants from GlaxoSmithKline and Grifols.

Open access This is an open access article distributed in accordance with the Creative Commons Attribution Non Commercial (CC BY-NC 4.0) license, which permits others to distribute, remix, adapt, build upon this work non-commercially, and license their derivative works on different terms, provided the original work is properly cited, appropriate credit is given, any changes made indicated, and the use is non-commercial. See: http://creativecommons.org/licenses/by-nc/4.0/.

(c) Author(s) (or their employer(s)) 2018. Re-use permitted under CC BY-NC. No commercial re-use. See rights and permissions. Published by BMJ.

BMJ Open 2018;8:e022051corr1. doi:10.1136/bmjopen-2018-022051corr1

D) Check for updates 
Correction: Real-world effectiveness evaluation of

budesonide/formoterol Spiromax for the management of

asthma and chronic obstructive pulmonary disease in the UK

Voorham J, Roche N, Benhaddi H, et al. Real-world effectiveness evaluation of budesonide/formoterol Spiromax for the management of asthma and chronic obstructive pulmonary disease in the UK. BMJ Open 2018;8:e022051. doi: 10.1136/ bmjopen-2018-022051.

It has come to light that Figure 1 (patient flow diagram [prior to matching]) in the previously published article contains errors, as follows:

- The numbers of BF Turbuhaler patients in the matched study cohort were erroneously given as 253 with asthma and 132 with COPD. These numbers should instead have been 743 and 348 , respectively.

- The numbers of patients in the combined cohort who were using FS Accuhaler/ Diskus and using BF Turbuhaler were erroneously given as 40540 and 50351 . These numbers should instead have been 40550 and 50 761, respectively.

- A footnote stating that duplicate patients between groups were removed for 1187 patients using FS Accuhaler/Diskus and 965 patients using BF Turbuhaler was omitted.

These errors have been addressed in the corrected version of the figure that is provided together with this correction notice. See the corrected figure below:

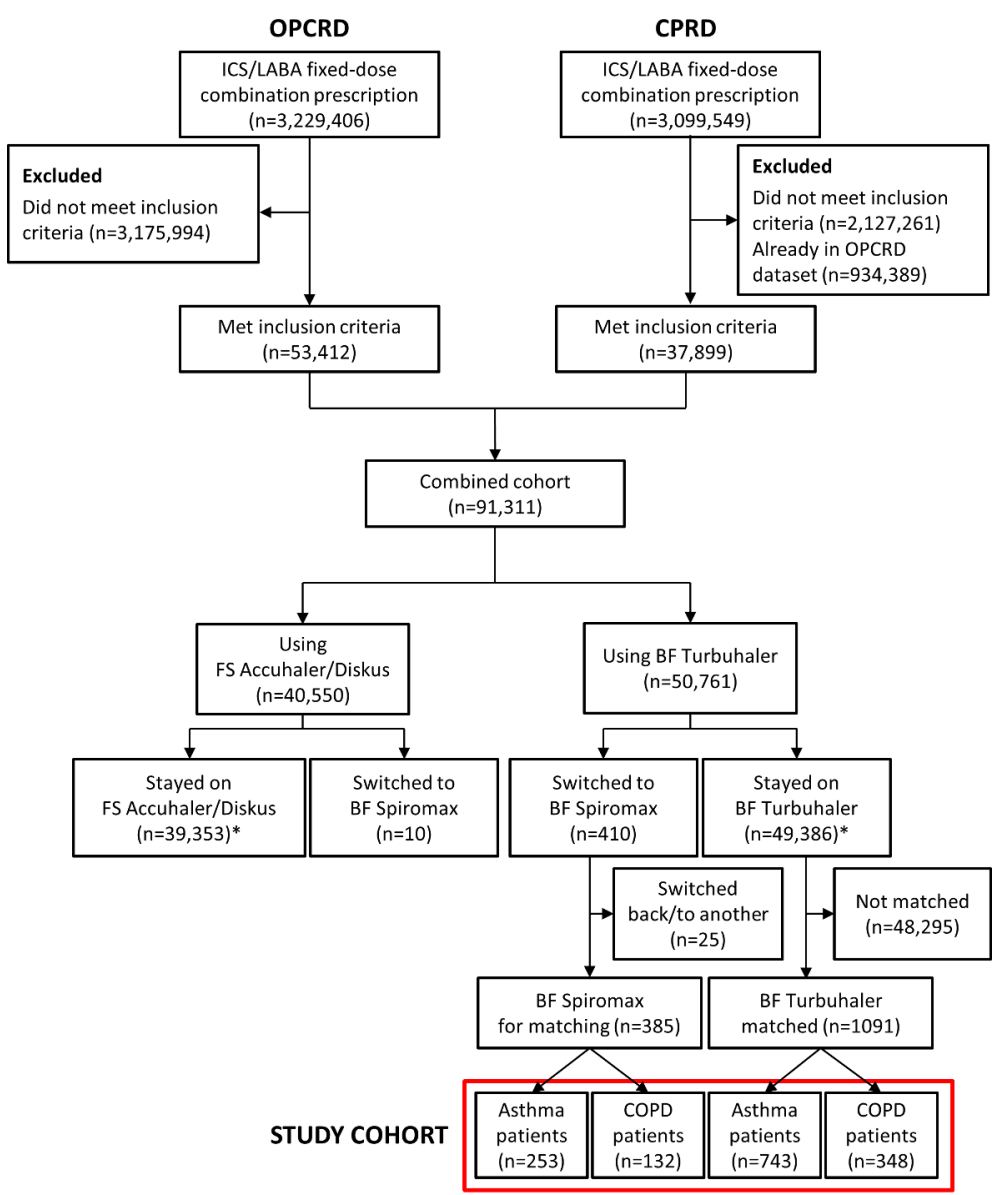

*Duplicate patients between groups were removed for 1,187 patients using FS Accuhaler/Diskus and 965 patients using BF Turbuhaler 
Open access This is an open access article distributed in accordance with the Creative Commons Attribution Non Commercial (CC BY-NC 4.0) license, which permits others to distribute, remix, adapt, build upon this work non-commercially, and license their derivative works on different terms, provided the original work is properly cited, appropriate credit is given, any changes made indicated, and the use is non-commercial. See: http://creativecommons.org/licenses/by-nc/4.0/.

C C Author(s) (or their employer(s)) 2019. Re-use permitted under CC BY-NC. No commercial re-use. See rights and permissions. Published by BMJ.

BMJ Open 2019;9:e022051corr2. doi:10.1136/bmjopen-2018-022051corr2

(D) Check for updates 